\title{
Perfluorooctane sulfonate influences feeding behavior and gut motility via the hypothalamus
}

\author{
AKIHIRO ASAKAWA ${ }^{1}$, MEGUMI TOYOSHIMA ${ }^{1}$, MINEKO FUJIMIYA ${ }^{2}$, KOUJI HARADA ${ }^{1}$, \\ KOJI ATAKA ${ }^{2}$, KAYOKO INOUE ${ }^{1}$ and AKIO KOIZUMI ${ }^{1}$ \\ ${ }^{1}$ Department of Health and Environmental Sciences, Kyoto University Graduate School of Medicine, Kyoto 606-8501; \\ ${ }^{2}$ Department of Anatomy, Shiga University of Medical Science, Shiga 520-2192, Japan
}

Received December 22, 2006; Accepted January 30, 2007

\begin{abstract}
Perfluorinated compounds (PFCs) have been employed as surface treatment agents in a variety of products. Perfluorooctane sulfonate (PFOS) and perfluorooctanoic acid (PFOA) are the two most commonly found PFCs in the environment and human blood. We investigated the effects of PFOS and PFOA on feeding behavior. PFOS or PFOA was administered intracerebroventricularly in mice or rats. Following administration, food intake, gastroduodenal motility, gastric emptying, gene expression of hypothalamic neuropeptides, and c-Fos expression along with immunoreaction for urocortin 2 in the paraventricular nucleus (PVN) were determined. Centrally administered PFOS and PFOA decreased food intake. Administration of PFOS decreased gastric emptying and disrupted the fasted motor activity in the antrum and duodenum. The gene expression of urocortin 2 in the hypothalamus and c-Fos expression and immunoreaction for urocortin 2 in the PVN were increased by the action of PFOS. A centrally administered corticotropin-releasing factor type 2 receptor (CRFR2) antagonist blocked PFOS-induced anorexia. These findings indicate that PFOS and PFOA influence feeding behavior. This effect is mediated via the activation of hypothalamic urocortin 2 and CRFR2, and the suppression of gastroduodenal motor activity. These observations indicate that PFCs may act centrally to influence behavior and physiological functions in humans.
\end{abstract}

\section{Introduction}

Perfluorinated compounds (PFCs) have been industrially manufactured for over 40 years. Of these PFCs, perfluoro-

Correspondence to: Dr Akio Koizumi, Department of Health and Environmental Sciences, Kyoto University Graduate School of Medicine, Kyoto 606-8501, Japan

E-mail:koizumi@pbh.med.kyoto-u.ac.jp

Key words: perfluorooctane sulfonate, perfluorooctanoic acid, feeding behavior, gut motility, hypothalamus, neuropeptides, urocortin, corticotropin-releasing factor receptor octane sulfonate (PFOS) and perfluorooctanoic acid (PFOA) are end products in the environment (1-3). Due to resistance to biodegradation in the ecological system and their amphilic nature, they are biomagnified in humans as well as wild animals (4-8). Human serum levels have been shown to be increasing significantly in recent years, raising an alarming concern about the effects on human health $(5,7)$.

Toxicological evaluations have revealed that these chemicals have a potent anorexic effect in rodents and monkeys $(8,9)$. Austin et al recently reported that PFOS inhibited food consumption and body weight gain, and was accumulated specifically in the hypothalamus (10). With these pieces of evidence and their structural mimicry of natural medium-size free fatty acids, one may reasonably hypothesize that PFOS and PFOA inhibit food consumption and body weight gain through direct action on the satiety center. Since this center controls not only eating behavior but also bridges energy homeostasis with emotion, this effect on the satiety center is critically important for a proper evaluation of the hazard potential of these chemicals (11).

The primary aim of the present study was to characterize the toxicity of PFOS and PFOA on the satiety center. To address the question of whether or not PFOS and PFOA have a direct action on the hypothalamus, we dosed animals by intracerebroventricular (ICV) administration and evaluated not only eating behavior but also gut motility as a peripheral signal from the hypothalamus.

\section{Materials and methods}

Animals and chemicals. The study protocol was approved by the Animal Research Ethics Committee of Kyoto University's Institutional Review Board. Animals were kept and handled according to the guidelines of the Animal Research Committee, Graduate School of Medicine, Kyoto University. We used male ddy mice (34-37 g, 8-9 weeks of age; Japan SLC Inc., Shizuoka, Japan), and male Wistar rats (230-280 g, 8-10 weeks of age; CLEA Japan Inc., Tokyo, Japan). The mice and rats were housed individually in a regulated environment $\left(24 \pm 2^{\circ} \mathrm{C}, 50 \pm 10 \%\right.$ humidity, $14: 10 \mathrm{~h}$ light:dark cycle with light on at 7:00 a.m.). Food and water were available ad libitum except as indicated. They were each used only once in the experiment. Heptadecafluorooctane sulfonic acid potassium 
salt (PFOS; FW 538.22; purity >98\%) and pentadecafluorooctanoic acid ammonium salt (PFOA; FW 431.10; purity $>98 \%$ ) were purchased from Fluka Chemical Corp. (WI, USA). Antisauvagine-30 (FW 3650.3; purity >95\%) was purchased from Phoenix Pharmaceuticals, Inc. (CA, USA). The Yanaihara Institute Inc. (Shizuoka, Japan) produced antibodies against urocortin 2. Before administration, drugs were diluted in artificial cerebrospinal fluid (ACSF) containing $1 \%$ DMSO that also served as control solutions.

ICV substance application. For ICV administration, the mice were anesthetized with sodium pentobarbital $(80-85 \mathrm{mg} / \mathrm{kg}$ IP) and placed in a stereotaxic instrument 7 days before experiments. A hole was made in each mouse skull using a needle inserted $0.9 \mathrm{~mm}$ lateral to the central suture and $0.9 \mathrm{~mm}$ posterior to the bregma. A 24-gauge cannula (Safelet-Cas, Nipro Corp., Osaka, Japan) beveled at one end over a distance of $3 \mathrm{~mm}$ was implanted into the third cerebral ventricle for ICV administration. The cannula was fixed to the skull using dental cement and capped with silicon without an obtruder. A 27-gauge administration insert was attached to a microsyringe using PE-20 tubing.

To evaluate gastroduodenal motility, rats were anesthetized using sodium pentobarbital $(50 \mathrm{mg} / \mathrm{kg} \mathrm{IP})$, placed in a stereotaxic apparatus, and implanted with a guide cannula (25-gauge; Eicom Corp., Kyoto, Japan), which reached the right lateral ventricle. The stereotaxic coordinates were $0.8 \mathrm{~mm}$ posterior to the bregma, $1.5 \mathrm{~mm}$ right lateral to the midline, and $3.5 \mathrm{~mm}$ below the outer surface of the skull. The guide cannula was secured using dental cement and anchored by 2 stainless steel screws fixed on the dorsal surface of the skull. After surgery, a dummy cannula (Eicom Corp.) was inserted into each guide cannula, and a screw cap (Eicom Corp.) was placed on the guide cannula to prevent blockage. The animals were allowed to recover for 7 days after this operation.

Feeding tests. Before the feeding tests, mice were deprived of food for $16 \mathrm{~h}$ with free access to water. A standard diet (F-2, $3.73 \mathrm{kcal} / \mathrm{g}$, Funahashi Farm Corp., Chiba, Japan) was used. For food-deprived mice, drugs were administered at 10:00 a.m. The drug was dissolved in ACSF containing 1\% DMSO to a final volume of $4 \mu \mathrm{l}$ for ICV administration. Food intake was measured by subtracting uneaten food from initially premeasured food at $20 \mathrm{~min}, 1,2,4,12$ and $24 \mathrm{~h}$ after administration and checking the food spillage.

Gastroduodenal motility. Gastroduodenal motility was measured in conscious freely moving rats by the manometric method. At 7 days after the brain surgery, the rats were deprived of food and given free access to water for $16 \mathrm{~h}$ prior to the abdominal operation. They were anesthetized with pentobarbital sodium $(50 \mathrm{mg} / \mathrm{kg} \mathrm{IP})$. Next, a motility recording device was implanted as follows. Two open-tipped catheters (3-Fr, 1-mm diameter; Atom Medical Corp., Tokyo, Japan) were inserted into the gastric body and duodenum for manometric measurement, with their tips placed at the gastric antrum and $3 \mathrm{~cm}$ distal from the pylorus. The catheters were held in place by purse-string sutures at the point of exit from the gastric and duodenum walls, brought out together through the abdominal wall musculature, tunneled subcutaneously to the back of the neck and sutured to the skin. After 1 week, the animals were subjected to a 16 -h fast prior to the commencement of the experiment. On the day of the experiment, a manometric catheter was connected to a pressure transducer (TP-400T; Nihon Kohden Corp., Tokyo, Japan) and connected to an infusion swivel (dual type, 20-gauge; Instech Laboratories Inc., PA, USA) to allow free movement. The catheter was continuously infused with bubble-free $0.9 \%$ saline at a rate of $1.5 \mathrm{ml} / \mathrm{h}$ by using a low compliance capillary infusion system with a heavy-duty pump (CVF-3100; Nihon Kohden Corp.). The PFOS (300 $\mu \mathrm{g} / \mathrm{kg}$ ) was dissolved in ACSF containing $1 \%$ DMSO to a final volume of $10 \mu 1$ for ICV administration.

Gastric emptying. Before the experiments for gastric emptying, mice were deprived of food for $16 \mathrm{~h}$ with free access to water. The fasted mice had free access to preweighed pellets for $1 \mathrm{~h}$. They were then intracerebroventricularly administered PFOS (100-300 $\mu \mathrm{g} / \mathrm{kg}$ ) or vehicle. The mice were deprived of food again for $2 \mathrm{~h}$ after administration. Food intake was measured by weighing the uneaten pellets. Mice were sacrificed by cervical dislocation $3 \mathrm{~h}$ after the start of the experiments. Immediately after, the stomach was exposed by laparotomy, quickly ligated at both the pylorus and cardia, and then removed. At this point the dry content was weighed. Contents were dried using a vacuum freeze-drying system (Model 77400; Labconco Corp., MO, USA). Gastric emptying was calculated according to the following formula: gastric emptying $(\%)=[1$ - (dry weight of food recovered from the stomach/weight of food intake)] $\mathrm{x}$ 100 .

Real-time-PCR. Mice were deprived of food for $16 \mathrm{~h}$ with free access to water. PFOS was infused at a rate of $75 \mu \mathrm{g} /$ $\mathrm{kg} / \mathrm{h}$ through an ICV catheter for $4 \mathrm{~h}$ before the mice were sacrificed by cervical dislocation. Immediately afterwards, the hypothalamic block was removed, frozen on dry ice, and stored at $-80^{\circ} \mathrm{C}$ until preparation of RT-PCR. Using the RNeasy Mini kit (Qiagen Inc., Tokyo, Japan) RNA was isolated from the hypothalamic block. Quantification of mRNA levels was performed with SYBR-Green chemistry (Qiagen Inc.) using a one-step RT-PCR reaction on a sequence detection system (ABI PRISM 7700; Applied Biosystems Japan, Tokyo, Japan). The reaction was performed under the standard conditions recommended by the manufacturer. The mouse GAPDH gene was used as an internal control. All expression data were normalized to the GAPDH expression level from the same individual sample. The following primers were used for RT-PCR: GAPDH forward, ATGGTGAAGGTCGGTGTGAA; and reverse, GAGTGGAGTCATACTGGAAC. Neuropeptide Y (NPY) forward, TTTCCAAGTTTCCACCCTCATC; and reverse, AGTGGTGGCATGCATTGGT. Agouti-related protein (AGRP) forward, GAGTTCCCAGGTCTAAGTCTGA ATG; and reverse, ATCTAGCACCTCCGCCAAAG. Orexin A forward, CGTAACTACCACCGCTTTAGCA; and reverse, TGCCATTTACCAAGAGACTGACAG. Melanin-concentrating hormone $(\mathrm{MCH})$ forward, GGA AGATACTGCAGAAAGATCCG; and reverse, ATG AAACCGCTCTCGTCGTT. Cocaine- and amphetamine- 


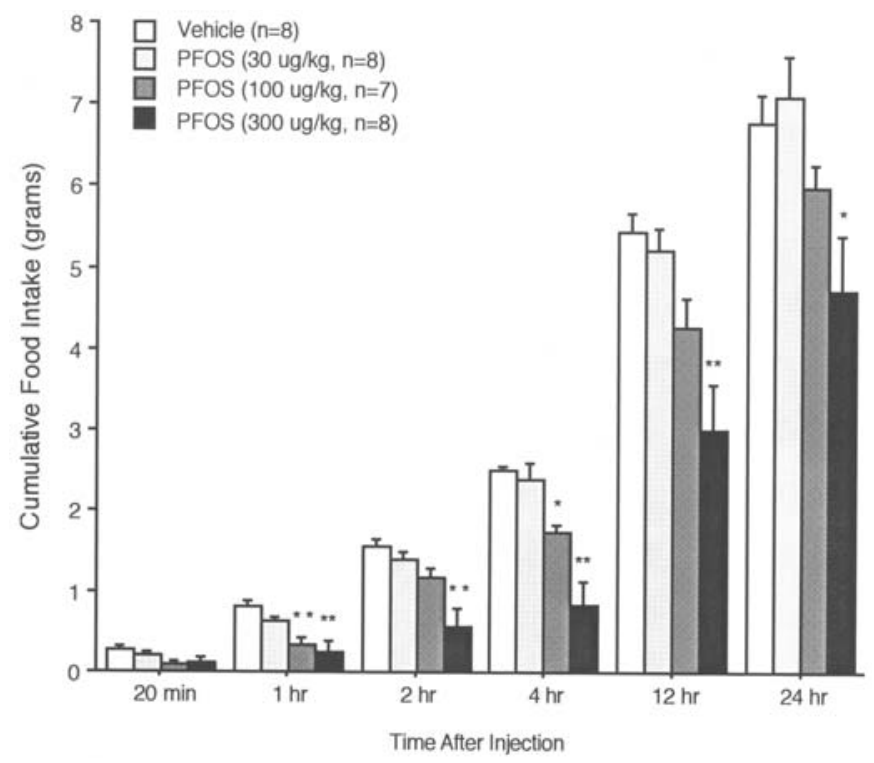

Figure 1. Inhibitory effects of ICV-administered PFOS $(30-300 \mu \mathrm{g} / \mathrm{kg})$ on cumulative food intake in food-deprived mice. Each bar represents the mean \pm SE. $n$ indicates the number of mice used. ${ }^{*} \mathrm{P}<0.05 ;{ }^{* *} \mathrm{P}<0.01$ by Scheffe's method.

regulated transcript (CART) forward, GCAGATCGAAGC GTTGCAA; and reverse, TTGGCCGTACTTCTTCTCG TAGA. Proopiomelanocortin (POMC) forward, GGCTTGC AAACTCGACCTCT; and reverse, TGACCCATGACGT ACTTCCG. Corticotropin-releasing factor (CRF) forward, CGCAGCCCTTGAATTTCTTG; and reverse, TCTGTTGA GATTCCCCAGGC. Urocortin 1 (UCN1) forward, ACTGT CCATCGACCTCACCTTC; and reverse, AAGGCTTTC GTGACCCCATA. Urocortin 2 (UCN2) forward, CCTCA GAGAGCTCCTCAGGTACC; and reverse, GGTAAGGG CTGGCTTTAGAGTTG. Urocortin 3 (UCN3) forward, CG CACCTCCAGATCAAAAGAA; and reverse, GGGTGCTC CCAGCTCCAT.

Immunohistochemistry. Mice were deprived of food for $16 \mathrm{~h}$ with free access to water. They were then subjected to ICV administration of PFOS $(300 \mu \mathrm{g} / \mathrm{kg})$ or vehicle. The mice were anesthetized with sodium pentobarbital (80-85 mg/kg IP) and perfused with $4 \%$ paraformaldehyde, $0.5 \%$ glutaraldehyde, and $0.2 \%$ picric acid in $0.1 \mathrm{M}$ phosphate buffer 90 min after administration. The brains were removed and postfixed with $4 \%$ paraformaldehyde and $0.2 \%$ picric acid in $0.1 \mathrm{M}$ phosphate buffer. The brains were cut into $20-\mu$ m-thick coronal sections in a cryostat. Sections that were cut through the paraventricular nucleus (PVN) of PFOS- or vehicle-administered rats were prepared for c-Fos immunohistochemistry using the $\mathrm{ABC}$ and $\mathrm{DAB}$ methods and immunofluorescence staining for urocortin 2. For single staining of c-Fos or urocortin 2, brain sections were incubated with c-Fos (rabbit polyclonal, Oncogene Research Products, CA, USA) or urocortin 2 antibodies (rabbit polyclonal, Yanaihara Institute Inc.), both diluted to 1:5000. In some sections, immunofluorescence double staining of c-Fos and urocortin 2 was performed. The sections were incubated with the mixture of c-Fos (goat polyclonal, Santa Cruz Biotechnology Inc., CA, USA) and
A
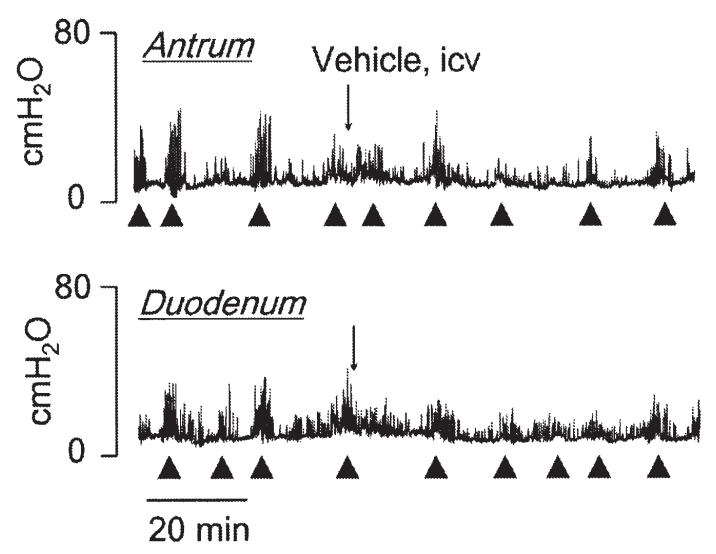

B
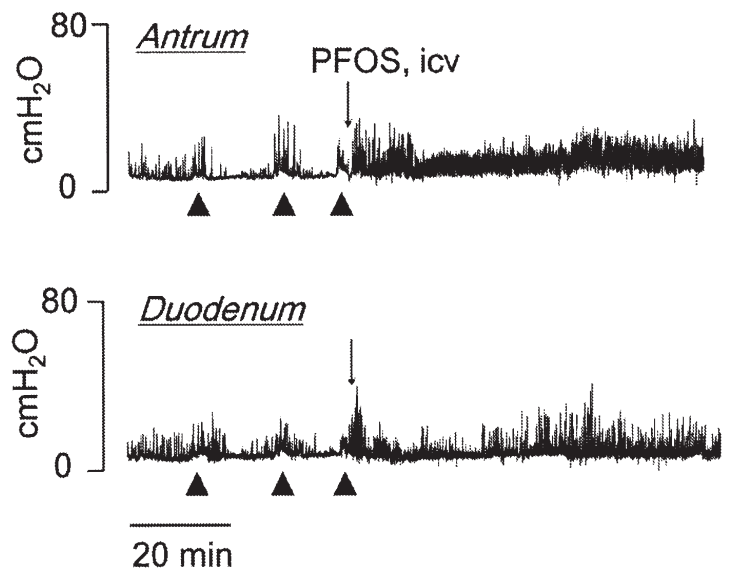

Figure 2. Effects of ICV-administered vehicle (A) and PFOS (300 $\mu \mathrm{g} / \mathrm{kg})$ (B) on the fasted motor activity of the antrum and duodenum $(n=3-5)$. The phase III-like contractions in the fasted motility are indicated by arrowheads.

urocortin 2 antibodies (rabbit polyclonal, Yanaihara Institute Inc.), both diluted to 1:5000. The sections were then incubated with a mixture of fluorescein isothiocyanate-labeled anti-goat IgG (Chemicon International Inc., CA, USA) and Cy3labeled anti-rabbit IgG (Chemicon International Inc.) diluted to $1: 1000$ and then observed under laser scanning microscopy (LSM 510; Carl Zeiss Inc. Japan, Tokyo, Japan).

Statistical analysis. ANOVA followed by Scheffe's method was used to assess differences among groups. Results are expressed as the mean value $\pm \mathrm{SE} . \mathrm{P}<0.05$ was considered to be statistically significant.

\section{Results}

To investigate whether PFOS and PFOA influenced feeding behavior, we first examined the effects of ICV administration of PFOS $(30-300 \mu \mathrm{g} / \mathrm{kg})$ on feeding in food-deprived mice. Centrally administered PFOS produced significant inhibitory feeding behavior in a dose-related manner (Fig. 1). Cumulative food intake was significantly decreased in the first $1 \mathrm{~h}$ after ICV administration and remained significantly decreased for a period of $24 \mathrm{~h}$. PFOA ( $300 \mu \mathrm{g} / \mathrm{kg}$ ) was found to have an equally anorexic effect as PFOS (data not shown). During the 


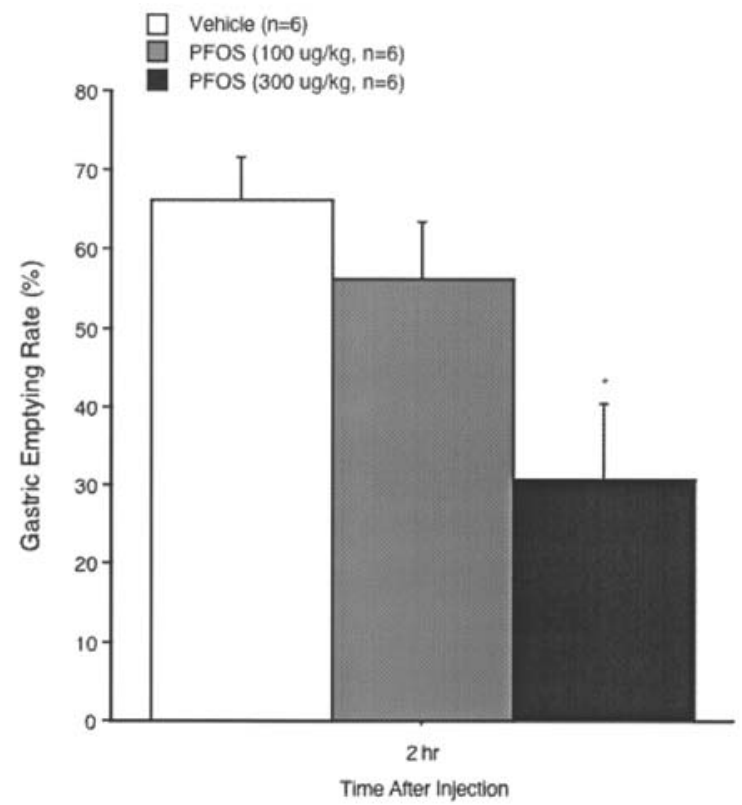

Figure 3. Inhibitory effects of ICV-administered PFOS (100-300 $\mu \mathrm{g} / \mathrm{kg}$ ) on the gastric emptying rate $2 \mathrm{~h}$ after administration. Each bar represents the mean \pm SE. $n$ indicates the number of mice used. ${ }^{*} \mathrm{P}<0.05$ by Scheffe's method.

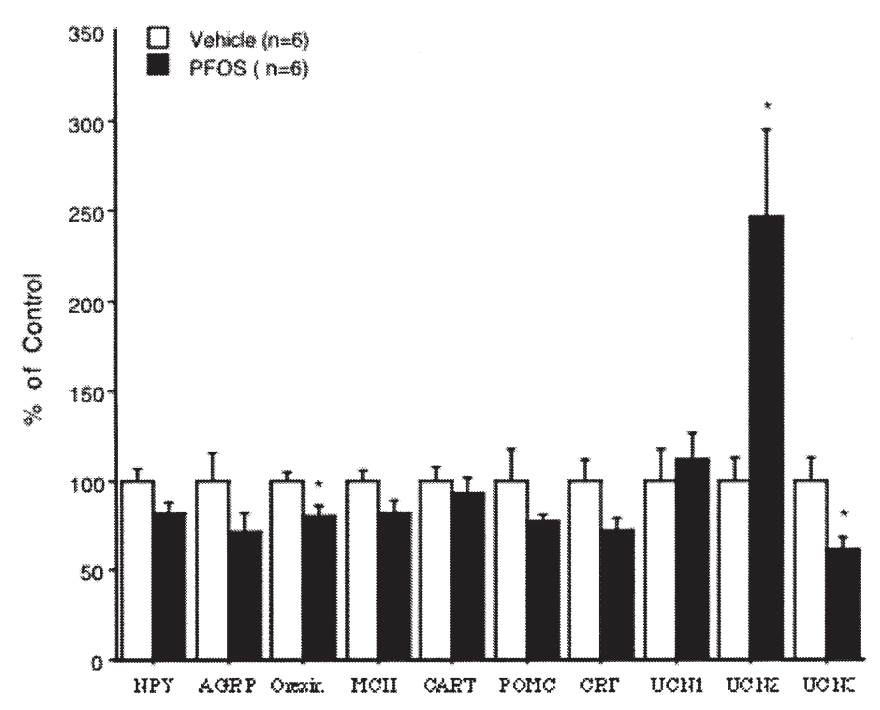

Figure 4. Effects of ICV infusion of PFOS (75 $\mu \mathrm{g} / \mathrm{kg} / \mathrm{h}$ for $4 \mathrm{~h}$ ) on hypothalamic peptide mRNA levels as assessed by RT-PCR in fooddeprived mice, and expressed as a percentage of the vehicle-treated control. Each bar represents the mean \pm SE. $n$ indicates the number of mice used. ${ }^{*} \mathrm{P}<0.05$ by Scheffe's method.

observed periods, mice were conscious and neither seizure nor sedation occurred.

Using conscious freely moving rat models, we examined whether or not PFOS influenced gastroduodenal motility. ICV administration of PFOS $(300 \mu \mathrm{g} / \mathrm{kg})$ disrupted the fasted motor activity in the antrum and duodenum in food-deprived rats (Fig. 2). The fed-like motor pattern induced by PFOS continued for over $1 \mathrm{~h}$ both in the stomach and duodenum $(\mathrm{n}=3-5)$. In addition, centrally administered PFOS (100-300 $\mu \mathrm{g} /$ $\mathrm{kg}$ ) decreased the gastric emptying rate $2 \mathrm{~h}$ after its administration in a dose-related manner (Fig. 3).

We examined the gene expression of hypothalamic neuropeptides in food-deprived mice following an ICV infusion of PFOS to evaluate the possibility that PFOS acts via the hypothalamic pathway. RT-PCR analysis showed that PFOS significantly increased the expression of urocortin 2 by $146 \%$ compared with the controls (Fig. 4). On the other hand, PFOS significantly decreased orexin and urocortin 3 mRNA expression by 20 and $19 \%$, respectively.

Next, we examined the effects of ICV administration of PFOS $(300 \mu \mathrm{g} / \mathrm{kg})$ on the number of c-Fos protein-expressing cells in the PVN of the hypothalamus. Central administration of PFOS resulted in an increase in the number of c-Fospositive cells in the PVN $[45.7 \pm 10.0$ vs. $11.6 \pm 6.48$ number/ section (control), $\mathrm{n}=3-4, \mathrm{P}<0.03$ ] (Fig. 5A). Immunohistochemical studies for urocortin 2 showed that PFOS increased the intensity of immunoreaction for urocortin 2 in the PVN compared with the controls $(n=3-4)$ (Fig. 5B). To examine the relationship between c-Fos expression and urocortin 2-containing neurons in the PVN, immunofluorescence double staining was performed. A urocortin 2positive reaction (red color) was observed in the cytoplasm of neuronal cell bodies located in the PVN, while a c-Fospositive reaction (green color) was observed in the nuclei of the PVN neurons (Fig. 5C). The results confirmed that most c-Fos-positive neurons overlapped with urocortin 2-positive neurons in the PVN.

Finally, we tested whether the inhibitory effect on feeding of PFOS $(300 \mu \mathrm{g} / \mathrm{kg})$ was blocked by the ICV administration of the selective corticotropin-releasing factor type 2 receptor (CRFR2) antagonist antisauvagine-30 (29.6 $\mu \mathrm{g} / \mathrm{kg}$ ) (Fig. 6). Antisauvagine-30 was confirmed to attenuate the inhibitory effect of PFOS on eating, suggesting that increased urocortin 2 signals suppressed peripheral signals to the gut through its receptor CRFR2.

\section{Discussion}

In this study, it is clearly demonstrated that PFOS and PFOA have anorexic activity. The anorexic effect of PFOS is mediated by its direct effect on the hypothalamus through upregulation of urocortin 2. Urocortin 2 mediated its effect through binding the receptor CRFR2 in PVN. This generated signal inhibited gut motility through an afferent pathway. Taken together, PFOS inhibited eating behavior and modulated gut motility through a direct effect on the brain. This is the first report on the toxicological activity in the hypothalamus by ubiquitous environmental toxicants in humans or animals.

Urocortin was found in 1995 as the second ligand for the CRF receptors (12). While CRF is mainly involved in the regulation of stress-related behavior and colonic motility, urocortin is mainly involved in the regulation of feeding behavior and gastric motility (13-15). Urocortin 2 was identified in 2001 as an endogenous ligand for CRFR2 $(16,17)$. The urocortin 2 gene is abundantly expressed in the hypothalamic nuclei, including the PVN, which are involved in the regulation of feeding and gut motility. Previous studies have shown that urocortin 2 suppresses food intake and 

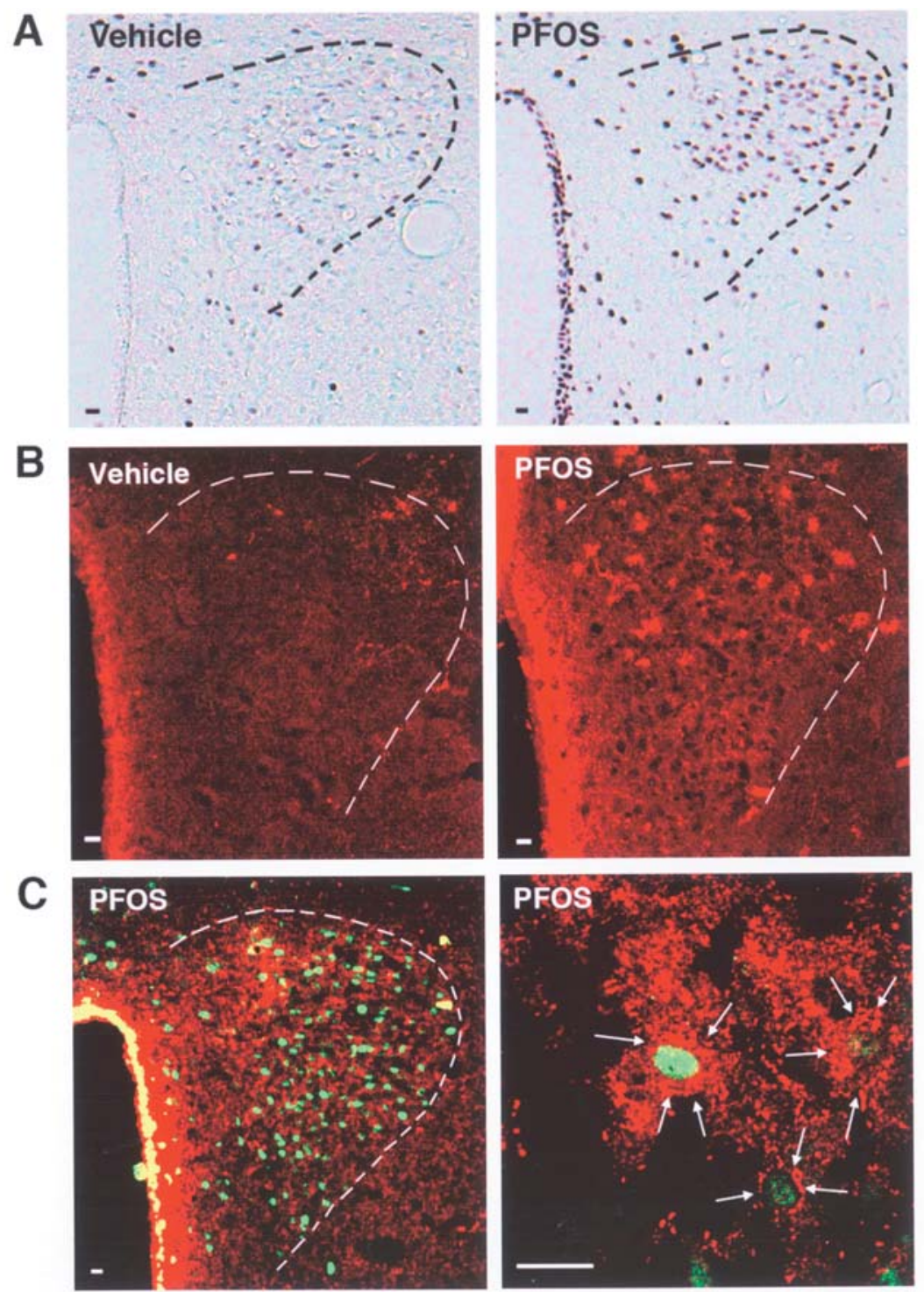

Figure 5. (A) Stimulatory effects of ICV-administered PFOS $(300 \mu \mathrm{g} / \mathrm{kg})$ on c-Fos expression in the PVN 90 min after administration (n=3-4). Photomicrographs of immunohistochemical demonstration of urocortin 2 (B), and overlap staining of c-Fos (green color) and urocortin 2 (red color) (C) in the PVN (n=3-4). Scale bars $=50 \mu \mathrm{m}$.

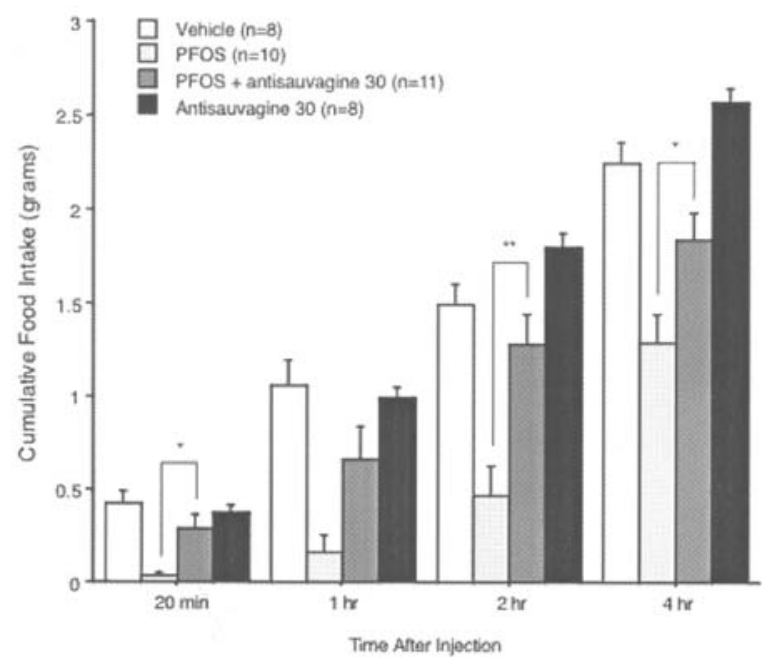

Figure 6. Antagonistic effects of antisauvagine-30 on the feeding induced by the ICV administration of PFOS $(300 \mu \mathrm{g} / \mathrm{kg})$ in food-deprived mice. Each bar represents the mean $\pm \mathrm{SE}$. $\mathrm{n}$ indicates the number of mice used. ${ }^{*} \mathrm{P}<0.05$; ${ }^{* *} \mathrm{P}<0.01$ by Scheffe's method. delays gastric emptying $(16,18)$. In addition, stimulation of the CRF2 receptor with urocortin 2 induces anxiogenic responses in a wide variety of rodent anxiety models (19). The involvement of CRFR2 was substantiated by a finding that selective CRFR2 antagonist antisauvagine-30 attenuated PFOS anorexic activity. These data collectively suggest that PFCs may modulate not only eating behavior but also changes in mood.

Upregulation of urocortin 2 expression by the administration of PFOS was unexpected and its mechanism remains an enigma. Although it is a member of the urocortin gene family, urocortin 2 seems to be unique in its regulation. Its promoter region is shorter than those of other members. Bioinformatic analysis (http://bimas.dcrt.nih.gov/molbio/ signal/) reveals that the urocortin 2 gene has TATA, GATA and GR elements but lacks a CRE element, which is commonly found in the promoters of the other members and provides responsiveness to cyclic AMP (20). It has also been shown recently that urocortin 2 decreases the cytosolic $\mathrm{Ca}$ concentration by closing L-type Ca channels (21). On the 
other hand, PFOS and PFOA have been shown to change the surface charge of the plasma membrane toward a less negative side and perturb L-type $\mathrm{Ca}^{2+}$ channel properties $(22,23)$. We thus hypothesize that perturbation of Ca-channel dynamics after ICV administration of PFOS might somehow be linked to the exaggerated response of urocortin 2 neurons. Further study is warranted for determining the mechanisms of the upregulation of urocortin 2 .

It has been reported that repeated dosing with PFOS by the intraperitoneal route also inhibits food intake in rodents and monkeys $(8,9)$. Considering that both PFOS and PFOA have demonstrated a high affinity for peroxisome proliferatoractivated receptor- $\alpha$ (PPAR- $\alpha$ ) (24), feeding is inhibited by an afferent pathway from the gut in addition to the efferent pathway by urocortin 2. Analogous to endogenous oleylethanolamide (OEA), which has a potent binding affinity for PPAR- $\alpha$, PFOS and PFOA may also inhibit food intake by the afferent pathway $(25,26)$. The putative afferent pathway which remains entirely unknown warrants elucidation.

PFOS and PFOA have been found in human serum samples from various countries as well as wild animals (4-8). The toxicological profile of PFOS and PFOA include carcinogenicity and developmental toxicity in animals (27-30). An epidemiological study suggested these chemicals are associated with elevated carcinogenic risks (31). In addition to the common toxicological profile, we have demonstrated that these chemicals have a toxic effect on PVN. Thus PFCs can be characterized as having certain common properties: persistence in the ecological system, mimicry of natural fatty acids and an amphilic character. These common properties may be used to classify a new subgroup of 'anorexigens', in a similar manner as chemicals which induce obesity are called 'obesitogens'.

In conclusion, this study indicates that PFOS and PFOA act centrally to suppress food intake. Their mechanism of action involves the activation of hypothalamic urocortin 2 and CRFR2 and the suppression of gastroduodenal motor activity. These observations indicate that PFCs may act centrally to influence not only eating behaviors but also mood. We believe that the accumulating evidence for such pleiotropic effects strongly suggests a need to reduce the level of PFCs now found ubiquitously throughout the world.

\section{Acknowledgements}

This study was supported by a Grant-in-Aid for Health Sciences Research from the Ministry of Health, Labor and Welfare of Japan (H15-Chemistry-004), Asahi Breweries Foundation and the Showa Shell Sekiyu Foundation (2005-A038).

\section{References}

1. Starkov AA and Wallace KB: Structural determinants of fluorochemical-induced mitochondrial dysfunction. Toxicol Sci 6: 244-252, 2002.

2. Olsen GW, Church TR, Larson EB, et al: Serum concentrations of perfluorooctanesulfonate and other fluorochemicals in an elderly population from Seattle, Washington. Chemosphere 54: 1599-1611, 2004.

3. Nakayama S, Harada K, Inoue K, Sasaki K, Seery B, Saito N and Koizumi A: Distributions of perfluorooctanoic acid (PFOA) and perfluorooctane sulfonate (PFOS) in Japan and their toxicities. Environ Sci 12: 293-313, 2005.
4. Giesy JP and Kannan K: Global distribution of perfluorooctanesulfonate in wildlife. Environ Sci Technol 35: 1339-1342, 2001.

5. Jin Y, Liu X, Li T, Qin H and Zhang Y: Status of perfluorochemicals in adult serum and umbilical blood in Shenyang. Wei Sheng Yan Jiu 33: 481-483, 2004.

6. Kannan K, Corsolini S, Falandysz J, et al: Perfluorooctanesulfonate and related fluorochemicals in human blood from several countries. Environ Sci Technol 38: 4489-4495, 2004.

7. Harada K, Koizumi A, Saito N, et al: Historical and geographical aspects of the increasing perfluorooctanoate and perfluorooctane sulfonate contamination in human serum in Japan. Chemosphere 66: 293-301, 2007.

8. Butenhoff J, Costa G, Elcombe C, et al: Toxicity of ammonium perfluorooctanoate in male cynomolgus monkeys after oral dosing for 6 months. Toxicol Sci 69: 244-257, 2002.

9. Seacat AM, Thomford PJ, Hansen KJ, Olsen GW, Case MT and Butenhoff JL: Subchronic toxicity studies on perfluorooctanesulfonate potassium salt in cynomolgus monkeys. Toxicol Sci 68: 249-264, 2002.

10. Austin ME, Kasturi BS, Barber M, Kannan K, MohanKumar PS and MohanKumar SM: Neuroendocrine effects of perfluorooctane sulfonate in rats. Environ Health Perspect 111: 1485-1489, 2003.

11. Kishi T and Elmquist JK: Body weight is regulated by the brain: a link between feeding and emotion. Mol Psychiatry 10: 132-146, 2005.

12. Vaughan J, Donaldson C, Bittencourt J, et al: Urocortin, a mammalian neuropeptide related to fish urotensin I and to corticotropin-releasing factor. Nature 378: 287-292, 1995.

13. Asakawa A, Inui A, Ueno N, Makino S, Fujino MA and Kasuga M: Urocortin reduces food intake and gastric emptying in lean and ob/ob obese mice. Gastroenterology 116: 1287-1292, 1999.

14. Dautzenberg FM and Hauger RL: The CRF peptide family and their receptors: yet more partners discovered. Trends Pharmacol Sci 23: 71-77, 2002

15. Nagata $\mathrm{T}$, Uemoto $\mathrm{M}$, Yuzuriha $\mathrm{H}$, et al: Intracerebroventricularly administered urocortin inhibits gastric emptying in mice. Int J Mol Med 15: 1041-1043, 2005.

16. Hsu SY and Hsueh AJ: Human stresscopin and stresscopinrelated peptide are selective ligands for the type 2 corticotropinreleasing hormone receptor. Nat Med 7: 605-611, 2001.

17. Reyes TM, Lewis K, Perrin MH, et al: Urocortin II: a member of the corticotropin-releasing factor (CRF) neuropeptide family that is selectively bound by type 2 CRF receptors. Proc Natl Acad Sci USA 98: 2843-2848, 2001.

18. Czimmer J, Million M and Tache Y: Urocortin 2 acts centrally to delay gastric emptying through sympathetic pathways while CRF and urocortin 1 inhibitory actions are vagal dependent in rats. Am J Physiol Gastrointest Liver Physiol 290: G511-G518, 2006.

19. Bruijnzeel AW and Gold MS: The role of corticotropinreleasing factor-like peptides in cannabis, nicotine, and alcohol dependence. Brain Res Rev 49: 505-528, 2005.

20. Zhao L, Donaldson CJ, Smith GW and Vale WW: The structures of the mouse and human urocortin genes (Ucn and UCN). Genomics 50: 23-33, 1998.

21. Tao J, Zhang Y, Soong TW and Li S: Expression of urocortin 2 and its inhibitory effects on intracellular $\mathrm{Ca}(2+)$ via L-type voltage-gated calcium channels in rat pheochromocytoma (PC12) cells. Neuropsychopharmacology 31: 2600-2609, 2006.

22. Harada K, Xu F, Ono K, Iijima T and Koizumi A: Effects of PFOS and PFOA on L-type Ca2+ currents in guinea-pig ventricular myocytes. Biochem Biophys Res Commun 329: 487-494, 2005.

23. Matsubara E, Harada K, Inoue K and Koizumi A: Effects of perfluorinated amphiphiles on backward swimming in Paramecium caudatum. Biochem Biophys Res Commun 339: 554-561, 2006.

24. Vanden Heuvel JP, Thompson JT, Frame SR and Gillies PJ: Differential activation of nuclear receptors by perfluorinated fatty acid analogs and natural fatty acids: a comparison of human, mouse, and rat peroxisome proliferator-activated receptor-alpha, -beta, and -gamma, liver $X$ receptor-beta, and retinoid X receptor-alpha. Toxicol Sci 92: 476-489, 2006.

25. Fu J, Gaetani S, Oveisi F, et al: Oleylethanolamide regulates feeding and body weight through activation of the nuclear receptor PPAR-alpha. Nature 425: 90-93, 2003. 
26. Proulx K, Cota D, Castaneda TR, et al: Mechanisms of oleylethanolamide-induced changes in feeding behavior and motor activity. Am J Physiol Regul Integr Comp Physiol 289: R729-R737, 2005.

27. Kennedy GL, Butenhoff JL, Olsen GW, et al: The toxicology of perfluorooctanoate. Crit Rev Toxicol 34: 351-384, 2004.

28. Lau C, Butenhoff JL and Rogers JM: The developmental toxicity of perfluoroalkyl acids and their derivatives. Toxicol Appl Pharmacol 198: 231-241, 2004.
29. Luebker DJ, York RG, Hansen KJ, Moore JA and Butenhoff JL: Neonatal mortality from in utero exposure to perfluorooctanesulfonate (PFOS) in Sprague-Dawley rats: dose-response, and biochemical and pharmacokinetic parameters. Toxicology 215: 149-169, 2005.

30. Olsen GW, Huang HY, Helzlsouer KJ, Hansen KJ, Butenhoff JL and Mandel JH: Historical comparison of perfluorooctanesulfonate, perfluorooctanoate, and other fluorochemicals in human blood. Environ Health Perspect 113: 539-545, 2005.

31. Alexander BH, Olsen GW, Burris JM, Mandel JH and Mandel JS: Mortality of employees of a perfluorooctanesulphonyl fluoride manufacturing facility. Occup Environ Med 60: 722-729, 2003. 